\title{
Evaluation of the effects of tetrapleura tetraptera extract and clomiphene citrate to determine influence of reproductive hormones and estrous cycle on leukocyte counts: novel evidence for a potential developmental link between luteinizing hormone and MID cells
}

\begin{abstract}
Estrous cycle influences circulating leukocyte count via reproductive hormones. Tetrapleura tetraptera extract has been shown to cause an increase in leukocyte count. Our previous work showed that Tetrapleura tetraptera pod extract inhibited LH and estrogen around ovulation stage. Therefore, the present study evaluated the effects of Tetrapleura tetraptera extracts and clomiphene citrate on leukocyte counts in order to determine whether the varying reproductive hormones secreted in both extracts and drug, and estrous cycle caused alteration in leukocyte counts.

Twenty eight adult female rats were selectively divided into 4 groups $(\mathrm{n}=7)$ according to their estrous phases. The group A served as control. Group B rats were administered 1mg/ $\mathrm{kg}$ of clomiphene citrate daily. Group C and D rats were administered 50 and $200 \mathrm{mg} / \mathrm{kg}$ of seed and pod extracts daily. Results showed that total WBC count was significantly reduced $(\mathrm{P}<0.05)$ in proestrus Group B. Total WBC, and lymphocyte counts remained unchanged. Neutrophil count was significantly reduced $(\mathrm{P}<0.05)$ in estrus Group $\mathrm{C}$. The MID cell count was significantly reduced in estrus Group C and D. The total WBC counts, lymphocyte count, serum FSH, estrogen and glucocorticoid levels were not statistically significant. Serum LH was significantly high $(\mathrm{P}<0.05)$ in proestrus Group B. Serum LH was significantly low in estrus Group C and D. Results showed that the significant reduction in the neutrophil in Group D is independent of the hormones and estrous cycle but dependent on dose concentration of Tetrapleura tetraptera extract. The significant elevation in MID cell count was associated with significant reduction in LH in Group C and D. However, total leukocyte count and MID cell count were significantly reduced and appeared to be associated with significant elevation in serum LH levels. The present study provides a novel idea of how LH affects MID cell population.
\end{abstract}

Keywords: neutrophil, MID cell, tetrapleura tetraptera, clomiphene citrate, luteinizing hormone, estrogen, white blood cell
Volume 5 Issue 6 - 2017

\author{
Agbai Emmanuel Onuka,' Nwanegwo \\ Collins Okechukwu, ${ }^{2}$ Kanno Mercy Maxine, ${ }^{3}$ \\ Anyaehie Ugochukwu Bond ${ }^{4}$ \\ 'Department of Human Physiology, Federal University of \\ Technology Owerri, Nigeria \\ 2Department of Physiology, Imo State University Owerri, \\ Nigeria \\ ${ }^{3}$ Genesis Health Care, USA \\ ${ }^{4}$ Department of Human Physiology, University of Nigeria, \\ Nigeria
}

\begin{abstract}
Correspondence: Agbai Emmanuel Onuka, Department of Physiology, School of Basic Medical Sciences, Federal University of Technology Owerri, Imo State, Nigeria, Tel +2348035976525, Email emmanuelagbai7@gmail.com
\end{abstract}

Received: August 01, 2017 | Published: December 29, 2017
Abbreviations: LH, luteinizing hormone; WBC, white blood cell; FSH, follicle-stimulating hormone

\section{Introduction}

The peripheral circulating white blood cell (WBC) or leukocyte count originate in the hematopoietic stem cells and develop along distinct differentiation in response to internal and external cues. ${ }^{1}$ The total number of WBC in the circulation is given as the peripheral WBC count and proportion of the total number of WBC represented by differentiated granulocytes (neutrophils, eosinophils and basophils), lymphocytes and monocytes is given as the differential WBC count, and are biomarkers for predicting acute infection, tissue damage, inflammation, diabetes, atherosclerosis and mortality. ${ }^{2-4}$

Moreover, Tetrapleura tetraptera is a perennial plant that belongs to Fabaceae family generally found in low land forest of tropical
Africa rich. The dried fruit is shiny, glabrous, dark purple brown with unpleasant aroma and rich in flavonoid, alkaloid and hydrogen cyanide. ${ }^{5,6}$ The fruit is used as popular seasoning in Southern Nigeria and has been shown to cause significant reduction in hematological indices in male rabbits ${ }^{7}$ and elevate hematological indices in female rats. ${ }^{8}$ Tetrapleura tetraptera has been shown to elevate total and differential WBC counts, ${ }^{8}$ but nothing is known on the mechanism of action of the extract-mediated elevation of WBC counts. However, the total WBC and differential WBC counts have been shown to vary across menstrual cycle with neutrophil increasing around ovulation and steadied in the mid-luteal phase associated with reproductive hormone variation whereas lymphocyte and MID cells remained unchanged during ovulation. ${ }^{9}$ There exists an interaction of reproductive hormones and immune system and this interaction has been attributed to reproductive hormone receptors on the immune cells. ${ }^{10}$ Another study also showed that female reproductive hormones 
strongly influence production and function of immune system cells and molecules. ${ }^{11}$ Several decades ago, Reisner demonstrated that estrogen facilitated leukocytosis in the bone marrow. ${ }^{12}$ It is well known that estrous cycle is dependent on the sex hormones.

Previous works have shown that Tetrapleura tetraptera pod extract inhibited luteinizing hormone ( $\mathrm{LH}$ ) and estrogen during proestrus stage in female rats ${ }^{13,14}$ thereby could affect circulating WBC population. Meanwhile, clomiphene citrate is mainly an antiestrogenic drug used in treating female infertility. ${ }^{15}$ We also demonstrate that clomiphene citrate caused significant elevation in LH level. ${ }^{14}$ Since Tetrapleura tetraptera pod extract caused opposite effects of clomiphene citrate on LH that is central to ovulation induction in females, therefore, the aim of the present study was to evaluate the effects of administration of Tetrapleura tetraptera extracts and clomiphene citrate on leukocyte counts in order to determine whether the varying reproductive hormones secreted namely follicle-stimulating hormone (FSH), LH, estrogen and glucocorticoid in both extracts and drug altered counts during ovulation.

\section{Materials and methods}

Twenty eight female albino Wistar rats were bought in the Veterinary Department, University of Nigeria, Nsukka and transported to Animal House of Department of Human Physiology, Madonna University Nigeria. The rats were kept in standard cages (Henan, China), received normal rat chow and tap water ad libitum. They were acclimatized for two weeks under 12 hours light/12 hours dark cycle in a room temperature of $24 \pm 2^{\circ} \mathrm{C}$. The rats were selectively divided into 4groups: A-D $(n=7)$ according to their estrous cycles. The control group A rats received only rat chow and tap water.

The experimental Group Brats were administered $1 \mathrm{mg} / \mathrm{kg}$ (orally) of clomiphene citrate daily according to Boyar et al. ${ }^{16}$ The experimental Group C rats were administered $200 \mathrm{mg} / \mathrm{kg}$ (orally) of Tetrapleura tetraptera pod extract daily according to Agbai et al. ${ }^{14}$ The experimental Group D rats were administered $50 \mathrm{mg} / \mathrm{kg}$ (orally) of Tetrapleura tetraptera seed extract daily according to Agbai et al. ${ }^{14}$ All administration lasted for 14days. Tetrapleura tetraptera dried fruits (weighing 950g) were bought from a local market, Afor Ogbe in Ahiazu Mbaise Local Government Area of Imo State. The pods were crushed with a pestle and the seeds were carefully removed from the pod. The pod fragments and seeds were sun-dried and ground into a coarse form respectively for Sohxlet method of extraction. $300 \mathrm{ml}$ of methanol (Sigma Aldrich, USA) was poured in Sohxlet containing powdered form of pod. Afterwards the methanol (solvent) was separated from the pod extract using Rotavapor device. The same method of extraction was used for the seed except the volume of methanol was reduced to $150 \mathrm{ml}$

Three grams tablets of clomiphene citrate $(50 \mathrm{mg} / \mathrm{tablet})$ was ground into a powdered form, suspended in methanol diluted with water and sieved with Whatman paper (no. 1) to remove excipients. The filtrate was taken as clomiphene citrate. All the rats received humane care according to the criteria outlined in the Guide for the Care of Laboratory Animals prepared by the National Academy Science. ${ }^{17}$ The estrous cycle was determined daily using the method described by Marcondes et al., ${ }^{18}$ and all the ratsin proestrus and estrus phases on the $14^{\text {th }}$ day were selected and sacrificed under urethane anesthesia before 12 noon. Blood was collected via cardiac puncture and blood was drawn using $5 \mathrm{ml}$ syringe and blood was collected in welllabeled EDTA bottles for evaluation of total white blood cell counts, neutrophil, lymphocyte and MID-cells (total value of mid-size cells such as monocytes, eosinophils and basophils counts) using electronic cell counter (Coulter Electronics, UK) and FSH, LH, estrogen and glucocorticoid levels using Enzyme Linked-Immunosorbent Assay (ELISA) methods.

\section{Results}

On the $14^{\text {th }}$ day the control group A and Group B rats exhibited proestrus phase while Group C and D exhibited estrus phase of the estrous cycle. Results showed that pod and seed extract did not cause statistically significant difference $(\mathrm{P}>0.05)$ in the total WBC count of Group C and D rats $\left(10,600 \pm 406.4 \mathrm{~mm}^{3}\right.$ and $\left.9,800 \pm 202.6 \mathrm{~mm}^{3}\right)$ compared with control group A rats $\left(10,900 \pm 190.9 \mathrm{~mm}^{3}\right)$. However, clomiphene citrate caused significant reduction in total WBC $(\mathrm{P}<0.05)$ of Group B rats $\left(7,400 \pm 60.7 \mathrm{~mm}^{3}\right)$ compared to control group, Group $\mathrm{C}$ and $\mathrm{D}$. There was statistically significant reduction $(\mathrm{P}<0.05)$ in neutrophil count of Group $\mathrm{C}$ rats $(25.0 \pm 1.0 \%)$ compared to control group A $(38.0 \pm 2.0 \%)$, Group B $(33.0 \pm 1.0 \%)$, and Group D $(34.0 \pm 2.0 \%)$. The level of lymphocytes was not statistically significant $(\mathrm{P}>0.05)$ in pod and extract-treated Group C $(70.0 \pm 1.00 \%)$ and $\mathrm{D}(61.0 \pm 5.00 \%)$ rats compared to control group $\mathrm{A}(59.0 \pm 6.00 \%)$ and clomiphene citrate-treated Group B $(63.0 \pm 5.00 \%)$ rats.

There was also statistically significant elevation $(\mathrm{P}<0.05)$ in MID cells of Group C $(5.0 \pm 0.50 \%)$ and Group D $(5.0 \pm 0.50 \%)$ rats

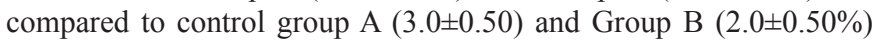
rats. There was no statistically significant difference $(\mathrm{P}>0.05)$ in FSH levels between control group A $(0.17 \pm 0.01 \mathrm{mIU} / \mathrm{ml})$ and experimental Group B, C and D $(0.19 \pm 0.02 \mathrm{mIU} / \mathrm{ml}, 0.21 \pm 0.02$ and $0.19 \pm 0.02 \mathrm{mIU} / \mathrm{ml})$. The pod extract caused significant reduction $(\mathrm{P}<0.05)$ in serum LH level of Group C $(0.17 \pm 0.30 \mathrm{mIU} / \mathrm{ml})$ and $\mathrm{D}$ $(0.13 \pm 0.06 \mathrm{mIU} / \mathrm{ml})$ rats compared to control group A $(0.34 \pm 0.8 \mathrm{mIU} /$ $\mathrm{ml})$ and Group B $(0.75 \pm 0.5 \mathrm{mIU} / \mathrm{ml})$ rats. The pod extract also caused significant reduction $(\mathrm{P}<0.05)$ in serum estrogen level of Group $\mathrm{C}$ rats $(58.49 \pm 10.04 \mathrm{pg} / \mathrm{ml})$ compared to control group A $(80.07 \pm 4.68 \mathrm{pg} /$ $\mathrm{ml})$, Group B $(79.57 \pm 1.28 \mathrm{pg} / \mathrm{ml})$ and Group D $(70.00 \pm 5.46 \mathrm{pg} / \mathrm{ml})$ rats. There was no statistically significant difference $(\mathrm{P}>0.05)$ in serum glucocorticoid level of Group B $(5.46 \pm 0.91 \mu \mathrm{g} / \mathrm{dl})$, Group C $(5.68 \pm 2.30 \mu \mathrm{g} / \mathrm{dl})$ and Group D $(4.49 \pm 1.27 \mu \mathrm{g} / \mathrm{dl})$ rats compared with control group A $(7.68 \pm 0.18 \mu \mathrm{g} / \mathrm{dl})$ rats (Table $1 \& 2)$.

Table I The effects of clomiphene citrate and Tetrapleura tetraptera on some hematological indices

\begin{tabular}{lllll}
\hline & Total WBC count $($ cubic $\mathbf{~ m m})$ & Neutrophil count (\%) & Lymphocyte count (\%) & MID cell count (\%) \\
\hline Control & $10,900 \pm 190.9$ & $38.0 \pm 2.0$ & $59.0 \pm 6.0$ & $3.0 \pm 0.50$ \\
Group B & $7,400 \pm 60.7^{*}$ & $33.0 \pm 1.0$ & $63.0 \pm 5.0$ & $2.0 \pm 0.50$ \\
Group C & $10,600 \pm 406.4$ & $25.0 \pm 1.0^{*}$ & $70.0 \pm 1.0$ & $5.0 \pm 0.50^{*}$ \\
Group D & $9,800 \pm 202.6$ & $34.0 \pm 2.0$ & $61.0 \pm 5.0$ & $5.0 \pm 0.50^{*}$ \\
\hline
\end{tabular}

Values $=$ mean \pm SEM

$* \mathrm{P}$ value significant $<0.05$

Citation: Onuka AE, Okechukwu NC, Maxine KM, et al. Evaluation of the effects of tetrapleura tetraptera extract and clomiphene citrate to determine influence of reproductive hormones and estrous cycle on leukocyte counts: novel evidence for a potential developmental link between luteinizing hormone and MID cells. Hematol Transfus Int J. 20I7;5(6):339-343. DOI: I0.15406/htij.20I7.05.00I40 
Table 2 The effects of clomiphene citrate and Tetrapleura tetraptera on some reproductive hormones

\begin{tabular}{lllll}
\hline & Follicle-stimulating hormone $(\mathrm{mlU} / \mathrm{ml})$ & Luteinizing hormone $(\mathrm{mlU} / \mathrm{ml})$ & Estrogen $(\mathrm{pg} / \mathrm{ml})$ & Glucocorticoid $(\mu \mathrm{g} / \mathrm{dl})$ \\
\hline Control & $0.17 \pm 0.01$ & $0.34 \pm 0.8$ & $80.07 \pm 46.8$ & $7.68 \pm 0.18$ \\
Group B & $0.19 \pm 0.02$ & $0.75 \pm 0.5$ & $79.57 \pm 1.2$ & $5.46 \pm 0.91$ \\
Group C & $0.21 \pm 0.02$ & $0.17 \pm 0.30^{*}$ & $58.49 \pm 10.04$ & $5.68 \pm 2.30$ \\
Group D & $0.19 \pm 0.02$ & $0.13 \pm 0.06^{*}$ & $70.00 \pm 5.46$ & $4.49 \pm 1.27$ \\
\hline
\end{tabular}

Values $=$ mean \pm SEM

$* P$ value significant $<0.05$

\section{Discussion}

The results showed that the pod and seed extract of Tetrapleura tetraptera did not cause significant change in the total WBC and lymphocyte but significantly reduced neutrophil count and elevated MID cells. In spite of the changes in the differential cells that sum up the total WBC count, the total WBC remained unchanged. Moreover, results in figure 1 showed that pod extract of Tetrapleura tetraptera caused significant reduction in neutrophil count. Study has shown that Tetrapleura tetraptera dried fruit extract elevate hematological indices in female rats. ${ }^{8}$ The current study does not support previous research in this area. However, the marked reduction in neutrophil count usually results from events that decrease the normal rate of production of these cells in the marrow or from processes that accelerate neutrophil destruction, sequestration, or egress from the circulation as well as apoptosis. Fleischer and colleagues have noted that noted some important flavonoid contents in Tetrapleura tetraptera namely 2', 4,4'-trihydroxychalcone, 2',3,4,4'-tetrahydroxychalcone (butein) and 4, 5,7-trihydroxyflavanone (apigenin). ${ }^{19}$ Studies have shown that high intake of these flavonoid compounds in Tetrapleura tetraptera can prevent many chronic diseases including allergy, and cancer. ${ }^{20,21}$ Because Tetrapleura tetraptera prevent allergy and cancer meant that immune system can be affected. More so, it well established that hematopoietic stem cell differentiation pathway into WBCs is dependent on granulocyte-colony stimulating factor and granulocyte/ monocyte-colony stimulating factor. ${ }^{22}$ Therefore, alteration in secretion of these colony stimulating factors impair proliferation and differentiation of leukocytes. Because studies have shown that flavonoids inhibit IL-1 $\beta$-stimulated granulocyte-colony stimulating factor expression and subsequent neutrophil differentiation as well as suppressing the expression of granulocyte/monocyte-colony stimulating factor ${ }^{23,24}$ could suggest that Tetrapleura tetraptera pod extract inhibited proliferation and differentiation processes required to necessitate neutrophil production resulting in the reduction in the peripheral neutrophil count.

Besides inhibition of granulocyte-colony stimulating factor and granulocyte/monocyte-colony stimulating factor, apigenin and chalcones have been shown to inhibit interleukins-6and blocked tumor necrosis factor- $\alpha .{ }^{25,26}$ Moore and colleagues have demonstrated that tumor necrosis factor- $\alpha$ injection caused activation of neutrophil. ${ }^{27}$ Since flavonoids inhibited tumor necrosis factor- $\alpha$ implied that activation of neutrophil will be inhibited therefore lends support to the idea that pod extract of Tetrapleura tetraptera significantly reduced circulating neutrophil count. In addition, interleukin- 6 has been shown to affect proliferation by targeting high proliferative potential-colony forming cells that share to a certain extent the characteristics of stem cell that produce leukocytes. ${ }^{28}$ To further support the reduction in neutrophil count by pod extract of Tetrapleura tetraptera, chalcone derivatives have been shown to inhibit neutrophil chemotaxis ${ }^{29}$ thereby inhibiting the recruitment and migration of neutrophils in the circulation thereby causing reduction in the circulating neutrophil.

Interestingly, the seed extract of Tetrapleura tetraptera did not cause significant change in the circulating neutrophil count. Since the seed extract is rich in flavonoid compounds such as apigenin, chalcones and butein, therefore, the same fall in neutrophil count in pod extract-treated Group C is expected in the Group D rats administered seed extract of Tetrapleura tetraptera suggesting the action of Tetrapleura tetraptera extract could be dose dependent because high concentration of flavonoids has been shown to inhibit proliferation of rat bone marrow stromal cells. ${ }^{30}$

On the other hand, there was no significant difference between extracts, clomiphene citrate and control group as far as lymphocyte count is concerned. Moreover, lymphocytes are responsible for specificity of adaptive immune responses. The $\mathrm{T}$ cells and $\mathrm{B}$ cells populate the lymphocyte pool and are lodged in lymphoid compartments with only tiny fraction of total lymphocyte population that continuously circulates between lymph and blood waiting for encounter with their antigen. ${ }^{31}$

The MID cell count was statistically elevated in the pod and seed extract-treated Group C and D rats. Previous studies have demonstrated that chalcones and apigenins exhibited inhibition of basophil degranulation and down-regulated high-affinity IgE receptor Fc\&RI expression on basophils. ${ }^{32,33}$ These report substantiate the fact that Tetrapleura tetraptera extracts caused increase in MID cell count because basophil counts contribute to MID cell count. Several studies have shown that flavonoid compounds inhibited eosinophil count in ovalbumin-induced asthma a well as inhibiting the release and gene expression of monocyte-chemoattractant protein-1,34,35 therefore, suggesting that eosinophils and monocytes might not be central in the elevation of MID cell count in this present study.

Several researchers have associated estrous cycle with variation in the WBC count. ${ }^{9,36,37}$ These researchers provided further evidences that secretory phase or ovulation of the menstrual cycle cause increases in total WBC count and neutrophil count. ${ }^{9,36}$ More so, the ovarian estrogen has been demonstrated to promote the release of neutrophils from the bone marrow. ${ }^{37}$

In the present study, the hormonal analysis did not confirm any significant differences between Tetrapleura tetraptera extracts, clomiphene citrate and control in terms of serum estrogen, glucocorticoid and FSH levels during proestrus and estrus phases of the estrous cycle. Moreover, it is worth mentioning that the estrous cycle corresponds to the secretory phase in menstruation. Previous studies demonstrated that Tetrapleura tetraptera extract inhibited LH and estrogen secretion during proestrus phase of the estrous cycle. ${ }^{11,13}$ 
Our current study contrast with what was previously thought that neutrophil reduction could have corresponded with low estrogen level. The marked observation to emerge from the data comparison was the reduction in serum LH level. However, data have shown that leuprolide acetate, a luteinizing hormone-releasing hormone agonist increases the myeloid progenitor cells in the bone marrow. ${ }^{38}$ The first studies on LH and hematopoietic stem/progenitor cell found that hematopoietic stem/progenitor cell express functional FSH and $\mathrm{LH}$ receptors that proliferate in vivo and in vitro in response to FSH and $\mathrm{LH}^{39}$ Abdelbaset-Ismail and colleagues further affirmed that LH stimulates growth of human hematopoietic/progenitor cells and mesenchymal cells in vivo and in vitro. ${ }^{40}$ These did not concur well with the reduction of LH by the Tetrapleura tetraptera pod and seed extracts association with changes in the neutrophil count, result is a confirmation of direct effect of Tetrapleura tetraptera on leukocyte production that is dose dependent. There appears also a non-alignment in the Tetrapleura tetraptera pod and seed extract-mediated elevation of MID cell count and low level of LH based on evidences that showed high level of LH facilitates hematopoietic stem/progenitor cell proliferation, however, the present result is a confirmation of the sparing effect of Tetrapleura tetraptera flavonoid content on basophil degranulation although this finding that low LH level is associated with high MID cell count could become a novel study.

To further analyze whether drug that induce ovulation via elevated LH can cause changes in the leukocyte count is a proven fact. Results indicated that clomiphene citrate caused significant reduction in total WBC count and MID cell count whereas neutrophil and lymphocyte counts were not affected. It is evident the decrease in the total WBC count emanated from the reduction in MID cells in the clomiphene citrate-treated Group B rats. This present result suggests that high level of LH inhibits MID cell production while low level of LH enhances MID cell production. This has provided further evidence that LH strongly affects MID cell count. Moreover, it has been reported that clomiphene citrate elevated neutrophil and basophil counts in cocks treated with $\geq 20 \mathrm{mg} / \mathrm{kg}$ of clomiphene citrate while lymphocyte, eosinophil and monocyte counts were not statistically significant ${ }^{41}$ suggesting that clomiphene citrate effect on leukocyte count is dose dependent.

\section{Conclusion}

The results of this study suggest that Tetrapleura tetraptera extract caused dose-related significant reduction in the neutrophil count independent of the estrous cycle and reproductive hormones. The extract further caused significant elevation in MID count associated with significantly low level of serum LH while clomiphene citrate caused significant reduction in MID cell count associated with significantly high level of serum LH. We have found a novel report that varying levels of serum LH affect MID cell count adding to a growing body of literature on LH effect on hematological indices. Our work clearly has some limitations on identifying the individual leukocyte cells in MID cells. Nevertheless we believe our work could be the basis for further work on the correlation between LH and monocytes, basophils and eosinophils.

\section{Acknowledgements}

The authors are grateful to the Department of Physiology, Faculty of Basic Medical Sciences, Madonna University Nigeria especially the chief technologist Mr Raymond Okonkwo for his technical assistance.

\section{Conflict of interest}

The author declares no conflict of interest.

\section{References}

1. Geissmann F, Manz MG, Jung S, et al. Development of monocytes, macrophages and dendritic cells. Science. 2010;327(5966):656-661.

2. Gkrania-Klotsas E, Ye Z, Cooper AJ, et al. Differential white blood cell count and type 2 diabetes: systematic review and meta-analysis of crosssectional and prospective studies. PLoS One. 2010;5(10):e13405.

3. Ortega E, Gilabert R, Nuñez I, et al. White blood cell count is associated with carotid and femoral atherosclerosis. Atherosclerosis. 2012;221(1):275-281.

4. Babio N, Ibarrola-Jurado N, Bulló M, et al. White blood cell counts as risk markers of developing metabolic syndrome and its components in the predimed study. PLoS One. 2013;8(3):e58354.

5. Aladesanmi AJ. Tetrapleura tetraptera: molluscicidal activity and chemical constituents. Afr J Tradit Complement Altern Med. 2007;4(1):23-36.

6. Uyoh EA, Ita EE, Nwofia GE. Evaluation of the chemical composition of Tetraptera tetrapleura (Schum and Thonn) Taub. accesions from cross river state, Nigeria. International Journal of Medicinal and Aromatic Plants. 2013;3(3):386-394.

7. Odesanmi SO, Lawal RA, Ojokuku SA. Hematological effects of ethanolic fruit extract of Tetrapleura tetraptera in male Dutch white rabbits. Res J Med Plants. 2010;4:213-217.

8. Jimmy EO, Ekpo AJD. Upgrading of lethal dose of Tetrapleura tetraptera extract enhances blood cell values. J Hematol Thrombo Dis. 2016;4:256.

9. Nowak J, Borkowska B, Pawlowski B. Leukocyte changes across menstruation, ovulation, and mid-luteal phase and association with sex hormone variation. Am J Hum Biol. 2016;8(5):721-728.

10. Wira CR, Sandoe CP. Hormonal regulation of immunoglobulins: influence of estradiol on immunoglobulins $A$ and $G$ in the rat uterus. Endocrinology. 1980;106(3):1020-1026.

11. Ansar Ahmed S, Penhale WJ, Talal N. Sex hormones, immune responses, and autoimmune diseases. Mechanism of sex hormone action. Am J Pathol. 1985;121(3):531-551.

12. Reisner EH. Tissue culture of bone marrow. II. Effect of steroid hormones on hematopoiesis in vitro. Blood. 1966;27(4):460-469.

13. El Izzi A, Benie T, Thieulant ML, et al. Inhibitory effects of saponins from Tetrapleura tetraptera on the LH released by cultured rat pituitary cells. Planta Med. 1990;56(4):357-359.

14. Agbai EO, Nwanegwo CO, et al. Tetraptera tetrapleura extract inhibited luteinizing hormone and estrogen secretion in clomiphene citrate-treated female Wistar albino rats. EJMP. 2016;2016:29103.

15. Dickey RP, Holtkamp DE. Development, pharmacology and clinical experience with clomiphene citrate. Hum Reprod Update. 1996;2(6):483506.

16. Marcondes FK, Bianchi FJ, Tanno AP. Determination of estrous cycle phases of rats: some helpful considerations. Braz J Biol. 2002;62(4A):609-614.

17. Boyar RM. Effects of clomiphene citrate on pituitary FSH, FSH$\mathrm{RF}$, and release of $\mathrm{LH}$ in immature and mature rats. Endocrinology. 1970;86(3):629-633.

18. Public health service policy on humane care and the use of laboratory animals. National Institute of Health (NIH), Washington USA: DC; 1986. p. $99-158$.

19. Fleischer TC, Komlaga G, Mensah AY, et al. Flavonoid constituents of the mature fruit of Tetrapleura tetraptera (schum. Et Thonn). Journal of Science and Technology. 2006;26(1):47-53.

20. Tanaka T, Takahashi R. Flavonoids and asthma. Nutrients. $2013 ; 5(6): 2128-2143$.

Citation: Onuka AE, Okechukwu NC, Maxine KM, et al. Evaluation of the effects of tetrapleura tetraptera extract and clomiphene citrate to determine influence of reproductive hormones and estrous cycle on leukocyte counts: novel evidence for a potential developmental link between luteinizing hormone and MID cells. Hematol Transfus Int J. 20I7;5(6):339-343. DOI: I0.15406/htij.2017.05.00140 
21. Romagnolo DF, Selmin OI. Flavonoids and cancer prevention: a review of the evidence. J Nutr Gerontol Geriatr. 2012;31(3):206-238.

22. Mehta HM, Malandra M, Corey SJ. G-CSF and GM-CSF in neutropenia. J Immunol. 2015;195(4):1341-1349.

23. Shih KS, Wang JH, Wu YW, et al. Aciculatin inhibitsgranulocyte colonystimulating factor production by human interleukin $1 \beta$-stimulated fibroblast-like synoviocytes. PLoS One. 2012;7(7):e42389.

24. Kawai M, Hirano T, Higa S, ,et al. Flavonoids and related compounds as anti-allergic substances. Allergol Int. 2007;56(2):113-123.

25. Kang $\mathrm{OH}$, Lee JH, Kwon DY. Apigenin inhibits release of inflammatory mediators by blocking NF- $\kappa \mathrm{B}$ activation pathways in the HMC-1 cells. Immunopharmacol Immunotoxicol. 2011;33(3):473-479.

26. Madan B, Batra S, Ghosh B. 2'-hydroxychalcone inhibits nuclear factorkappa B and blocks tumor necrosis factor-alpha and lipopolysaccharideinduced adhesion of neutrophils to human umbilical vein endothelial cells. Mol Pharmacol. 2000;58(3):526-534.

27. Moore FD, Socher SH, Davis C. Tumor necrosis factor and endotoxin can cause neutrophil activation through separate pathways. Arch Surg. 1991;126(1):70-73.

28. Testa NG, Dexter TM. The regulation of haematopoietic cell production In: Hoffbrand VA, et al. editors. Introduction to the haematopoietic system. 4th ed. Postgraduate haematology, London, UK: Arnold Publishers; 2001.

29. Bukhari SN, Tajuddin Y, Benedict VJ, et al. Synthesis and evaluation of chalcone derivatives as inhibitors of neutrophils' chemotaxis, phagocytosis and production of reactive oxygen species. Chem Biol Drug Des. 2014;83(2):198-206.

30. Chen KM, Ma HP, Ge BF, et al. Icariin enhances the osteogenic differentiation of bone marrow stromal cells but has no effects on the differentiation of newborn calvarial osteoblasts of rats. Pharmazie. 2007;62(10):785-789.

31. Alberts B, Johnson A, Lewis J, et al. Lymphocytes and cellular basis of adaptive immunity. 4th ed. Molecular biology of cell. New York, USA: Garland Science; 2002.
32. Middleton E, Drzewiecki G (1984) Flavonoid inhibition of human basophil histamine release stimulated by various agents. Biochem Pharmacol 33(21): 3333-3338.

33. Satomi Yano,Hirofumi Tachibana, Koji Yamada. Flavones suppress the expression of high-affinity IgE receptor FceRI in human basophilic KU812 cells. J Agric Food Chem. 2005;53(5):1812-1817.

34. Li J, Zhang B. Apigenin protects ovalbumin-induced asthma through regulation of The 17 cells. Fitoterapia. 2013;91:298-304.

35. Kowalski J, Samojedny A, Paul M, et al. Apigenin inhibits release and gene expression of monocyte chemoattractant protein 1 (MCP-1) in J774.2 macrophages. Wiad Lek. 2006;59(9-10):634-638.

36. Bain BJ, England JM. Variations in leucocyte count during menstrual cycle. Br Med J. 1975;2(5969):473-475.

37. Rosemary SP, Anita Devi M, Soniya I. Menstrual cycle and its relation with leukocyte count. IOSR Journal of Dental and Medical Sciences. 2014;13(1):65-67

38. Goldberg GL, King CG, Nejat RA, et al. Luteinizing hormone-releasing hormone enhances $\mathrm{T}$ cell recovery following allogeneic bone marrow transplantation. J Immunol. 2009;182(9):5846-5854.

39. Mierzejewska K, Borkowska S, Ewa Suszynska, et al. Hematopoietic stem/progenitor cells express several functional sex hormone receptors -novel evidence for a potential developmental link between hematopoiesis and primordial germ cells. Stem Cells and Development. 2015;24(8):927-937.

40. Abdelbaset-Ismail A, Suszynska M, Borkowska SJ, et al. Human hematopoietic stem/progenitor cells (HSPCs) and mesenchymal stromal cells (MSCs) express several functional pituitary and gonadal sex hormone receptors- identification of follicle stimulating hormone (FSH) and luteinizing hormone ( $\mathrm{LH})$ as new growth factors for HSPCs and MSCs. Blood 2015;126:2393.

41. Urom SMOC, Ukpabi H, Alum EA, et al. Effect of clomiphene citrate on hematology and serum biochemistry of Nigerian indigenous chicken. IJSTR. 2016;5(5):1-6. 